\title{
A case of the syndrome of inappropriate secretion of antidiuretic hormone (SIADH) associated with lupus erythematosus in the central nervous system
}

\author{
Hiroaki Hara $\cdot$ Hajime Hasegawa $\cdot$ Mizuki Iwanaga $\cdot$ \\ Tomonya Ogawa $\cdot$ Akihiko Matsuda $\cdot$ \\ Koichi Kanozawa $\cdot$ Hitoshi Kato $\cdot$ Tetsuya Mitarai
}

Received: 8 March 2012/ Accepted: 16 July 2012/Published online: 15 August 2012

(C) Japanese Society of Nephrology 2012

\begin{abstract}
We report on a case of the syndrome of inappropriate secretion of antidiuretic hormone (SIADH) associated with lupus erythematosus in the central nervous system (CNS). A 73-year-old woman with essential hypertension suddenly demonstrated consciousness disturbance. Upon her admission, laboratory data showed significant hyponatremia $(114 \mathrm{mEq} / \mathrm{L})$ and a lack of body fluid loss. Diminished free water excretion (urine osmolality $684 \mathrm{mOsm} / \mathrm{kg}$ ) and normal urine $\mathrm{Na}$ excretion (FENa $1.70 \%$ ) were consistent with the diagnosis of SIADH, which was confirmed by an inappropriately high concentration of plasma antidiuretic hormone (ADH) $(15.3 \mathrm{pg} / \mathrm{mL}$ at $256 \mathrm{mOsm} / \mathrm{kg}$ of plasma osmolality). The hyponatremia was corrected by a combination of oral water intake restriction and saline infusion with furosemide administration until the 20th hospital day. Simultaneously, the presence of exudative pleural effusion in both chest cavities, suggesting the existence of pleuritis, and high titer of anti-nuclear antibody (ANA, 5120 $\times$ ) and anti-doublestrand DNA antibody $(6500 \mathrm{IU} / \mathrm{mL})$, indicated the subclinical development of systemic lupus erythematosus (SLE), although the diagnostic criteria were not satisfied at that time. On the 34th hospital day, the sudden onset of unknown consciousness disturbance confirmed the diagnosis of SLE as CNS lupus. In previous case reports on SLE and/or SIADH, a few cases in which SLE and SIADH developed concomitantly regularly showed high immunological activities, as in our case. Some common
\end{abstract}

H. Hara $\cdot$ H. Hasegawa $(\varangle) \cdot$ M. Iwanaga $\cdot$ T. Ogawa .

A. Matsuda - K. Kanozawa $\cdot$ H. Kato - T. Mitarai

Department of Nephrology and Hypertension, Saitama Medical

Center, Saitama Medical University, 1981 Kamoda, Kawagoe,

Saitama 350-8550, Japan

e-mail: hase2126@saitama-med.ac.jp pathophysiological bases might be involved in the concomitant appearance of those disorders.

Keywords Systemic lupus erythematosus (SLE) . Syndrome of inappropriate secretion of antidiuretic hormone (SIADH) · CNS lupus · SLEDAI ·

Immune activity

\section{Introduction}

Systemic lupus erythematosus (SLE) is a systemic connective tissue disease resulting from autoimmune abnormalities. It targets almost every organ or tissue in the entire body. SLE with clinical signs related to central nervous system (CNS) disorders are considered to be a particular subtype of SLE, called CNS lupus. We recently experienced a patient who developed severe hyponatremia, with CNS lupus appearing in the late clinical phase.

Water and electrolyte disorders associated with SLE, including disruption of urine concentration ability, hypernatremia, abnormalities of calcium concentration, and disturbance of the acid-base balance, are not generally considered to be complications of SLE, but are believed to result from tubulointerstitial damage associated with lupus nephritis. However, our patient did not show any subjective or objective signs of lupus nephritis. The syndrome of inappropriate secretion of antidiuretic hormone (SIADH) is a clinical setting presenting dilutional hyponatremia caused by diminished excretion of free water and the sustained discharge of hypertonic urine resulting from inappropriate antidiuretic hormone (ADH) secretion. In general, many cases of SIADH are accompanied by intracranial or intratracheal disorders, or provoked as the adverse effects of medications such as chlorpropamide or carbamazepine. 
The remaining cases, i.e., SIADH of unknown origin, are classified as idiopathic SIADH. Interestingly, recent works suggest that the enhanced production and release of some cytokines might be involved in the genesis of both idiopathic SIADH and CNS lupus, in some cases demonstrating highly elevated autoimmune activity, as in the present case.

\section{Case report}

Our patient was a 73-year-old woman who was admitted to our hospital as an emergency case demonstrating coma. Beginning 3 weeks before admission, she was aware of general fatigue and loss of appetite, which appeared to be slowly progressive. Finally, on the day of admission, one of her family members happened to recognize that our patient was unconscious and made an emergency call. For the 10 years leading up to this event, she had been taking valsartan and trichlormethiazide after another hospital had diagnosed her with essential hypertension At the age of 53 years, she was diagnosed with Guillain-Barré syndrome, but had no history of consciousness disturbance or coma attack until the present admission. Just before admission to our hospital, she took some medications prescribed by the other hospital as follows; valsartan $80 \mathrm{mg} /$ day, trichlormethiazide $2 \mathrm{mg} /$ day, diazepam $2 \mathrm{mg} /$ day, tocopheryl acetate $100 \mathrm{mg} /$ day.

Upon admission, her condition of consciousness was evaluated as grade II-10 on the Japan Coma Scale (JCS), indicating a slight tendency toward somnolence. She showed a stable circulation state, with a heart rate of $65 \mathrm{bpm}$, along with systolic and diastolic blood pressures of 133 and $70 \mathrm{mmHg}$, respectively. Her body temperature was $36.2{ }^{\circ} \mathrm{C}$. There were no other significant physical findings in the region of the head, neck, chest, or abdomen. No abnormal neurological findings were observed. Table 1 shows the laboratory results of blood and urine tests upon admission. She showed remarkable hyponatremia $(114 \mathrm{mEq} / \mathrm{L})$, whereas her previous value of serum $\mathrm{Na}$ was $133 \mathrm{mEq} / \mathrm{L}$, recorded by the other hospital at a month before the admission. Therefore, this rapidly developed hyponatremia was assumed to be a principal cause of her consciousness disturbance. Despite the presence of hyponatremia, her urine showed inappropriately high osmolality, suggesting impaired free water excretion. Indeed, an inappropriate increase in plasma ADH concentration to the plasma osmolality was reported later on. An elevated concentration of human atrial natriuretic peptide (hANP) suggested that her body fluid state was hypervolemic, although her renin-angiotensin-aldosterone system was not suppressed at that time. Based on the laboratory results and clinical findings, she was diagnosed with hyponatremia associated with SIADH. She was then administered $1000 \mathrm{~mL}$ a day of physiological saline and $20 \mathrm{mg}$ a day of furosemide, accompanied by the restriction of oral fluid intake up to $300 \mathrm{~mL}$ a day. Upon admission, hypokalemia $(3.3 \mathrm{mEq} / \mathrm{L})$ associated with hyperkaliuria $(58.5 \mathrm{mEq} / \mathrm{L}$, FEK $15.5 \%$ ) was also noticed. Considering thiazide administration might have been involved in the accelerated $\mathrm{K}$ excretion, thiazide was discontinued upon admission, and oral $\mathrm{K}$ supplementation ( $32 \mathrm{mEq} /$ day) was started. After 7 days, serum $\mathrm{K}$ reached $4.4 \mathrm{mEq} / \mathrm{L}$ (FEK $23.3 \%$ ) and $\mathrm{K}$ supplementation was discontinued.

Her clinical course is shown in Fig. 1. Her consciousness disturbance was almost solved on the 13th hospital day, when the serum $\mathrm{Na}$ concentration reached approximately $130 \mathrm{mEq} / \mathrm{L}$. Saline infusion was reduced step-bystep and discontinued on the 24th hospital day. Even after this withdrawal, her serum $\mathrm{Na}$ concentration was stably maintained in the range $127-130 \mathrm{mEq} / \mathrm{L}$. Upon admission, our patient presented Raynaud's phenomenon accompanied by an elevation of anti-nuclear antigen (ANA) in the screening blood test. An additional immunological blood test demonstrated a significant increase in double-strand DNA antibody and a moderate increase in SS-A antibody, suggesting the possible existence of subclinical autoimmune disorders in our patient. A chest X-ray study and chest computed tomography (CT) scanning showed bilateral pleural effusion (Fig. 2). A laboratory test revealed that the effusion was exudative, as shown in Table 2. Because the existence of other disorders causing exudative pleural effusion, such as infectious pleuritis or pneumonia, was clinically excluded, serositis was strongly suggested. However, the criteria of the diagnostic guidelines of SLE, first presented by the American Rheumatology Association (ARA) in 1992, were not satisfied in our case, despite a series of advocating findings.

On the 34th hospital day, consciousness disturbance (JCS II-30) was suddenly presented again in association with aphasia and visual disturbance. Brain magnetic resonance imaging (MRI) did not show any findings compatible with cerebrovascular disorders, but revealed a subcortical T2-high lesion (Fig. 3), which would not be rarely observed in patients with CNS lupus [7]. In addition, as shown in Table 3, a laboratory test of the cerebrospinal fluid demonstrated increased cell count and protein concentration, accompanied by a high value of $\mathrm{IgG}$ index (0.68). Especially, the concentration of interleukin-6 in the cerebrospinal fluid was markedly increased $(386 \mathrm{pg} / \mathrm{mL}$; normal range $<4.3 \mathrm{pg} / \mathrm{mL}$ ). Based on those clinical and laboratory findings, it was considered that SLE-related complications in the central nervous system (CNS lupus) was developed in our patient. The serum titer of anti-DNA double-strand antibody, showing a high value even upon admission, was further elevated (from 6500 to $7500 \mathrm{IU} /$ 
Table 1 Laboratory test of blood and urine

\begin{tabular}{|c|c|c|c|}
\hline Urinalysis & & Immunology & \\
\hline Urine specific gravity & 1.006 & Total complement activity (CH50) (IU/L) & 46.9 \\
\hline Red blood cells (cells/HPF) & $5-9$ & Anti-nuclear antibody (speckled type) & $1: 5120$ \\
\hline White blood cells (cells/HPF) & $5-9$ & Anti-double strand DNA antibody (IU/mL) & 6500 \\
\hline Granular cast (/HPF) & $1-4$ & Anti-Ro/SSA antibody & Positive \\
\hline $\mathrm{pH}$ & 6.5 & Anti-La/SSB antibody & Negative \\
\hline Protein & Negative & Lupus anticoagulant (LAC) & Negative \\
\hline Sugar & Negative & Anti-cardiolipin antibody & Negative \\
\hline Urine chemistry & & Anti- $\beta 2$ glycoprotein 1 antibody & Negative \\
\hline$N$-acetyl- $\beta$-D-glucosaminase (IU/L) & 15.9 & $\operatorname{IgG}(\mathrm{mg} / \mathrm{dL})$ & 2979 \\
\hline$\beta 2$-Microglobulin (IU/L) & 2178 & $\operatorname{IgA}(\mathrm{mg} / \mathrm{dL})$ & 444.8 \\
\hline Urine creatinine (mg/dL) & 39.4 & $\operatorname{IgM}(\mathrm{mg} / \mathrm{dL})$ & 88.5 \\
\hline $\mathrm{Na}(\mathrm{mEq} / \mathrm{L})$ & 90 & Endocrinology & \\
\hline $\mathrm{Cl}(\mathrm{mEq} / \mathrm{L})$ & 168 & Adrenocorticotropic hormone $(\mathrm{pg} / \mathrm{mL})$ & 50.1 \\
\hline $\mathrm{K}(\mathrm{mEq} / \mathrm{L})$ & 15 & Antidiuretic hormone $(\mathrm{pg} / \mathrm{mL})$ & 15.3 \\
\hline Urine osmolality (mOsm/kg) & 684 & Free $\mathrm{T} 4(\mathrm{pg} / \mathrm{mL})$ & 1.85 \\
\hline Blood biochemistry & & Free $\mathrm{T} 3(\mathrm{pg} / \mathrm{mL})$ & 1.4 \\
\hline $\mathrm{Na}(\mathrm{mEq} / \mathrm{L})$ & 114 & Thyroid-stimulating hormone $(\mu \mathrm{IU} / \mathrm{mL})$ & 9.8 \\
\hline $\mathrm{Cl}(\mathrm{mEq} / \mathrm{L})$ & 78 & Cortisol $(\mu \mathrm{g} / \mathrm{dL})$ & 57.5 \\
\hline $\mathrm{K}(\mathrm{mEq} / \mathrm{L})$ & 2.5 & Aldosterone $(\mathrm{pg} / \mathrm{mL})$ & 137 \\
\hline Total protein $(\mathrm{g} / \mathrm{dL})$ & 8.9 & Plasma renin activity $(\mathrm{ng} / \mathrm{mL} / \mathrm{h})$ & 2 \\
\hline Albumin $(\mathrm{g} / \mathrm{dL})$ & 3.5 & Human atrial natriuretic peptide $(\mathrm{pg} / \mathrm{mL})$ & 111 \\
\hline Blood urea nitrogen $(\mathrm{mg} / \mathrm{dL})$ & 14 & Blood cell count & \\
\hline Creatinine (mg/dL) & 0.73 & White blood cells $(/ \mu \mathrm{L})$ & 9400 \\
\hline Estimated GFR (mL/min) & 59.3 & Hemoglobin $(\mathrm{g} / \mathrm{dL})$ & 9.8 \\
\hline Aspartate transaminase (IU/L) & 57 & Platelet $(/ \mu \mathrm{L})$ & $143 \times 10^{3}$ \\
\hline Alanine aminotransferase (IU/L) & 24 & Blood coagulation system & \\
\hline Lactate dehydrogenase (IU/L) & 675 & Prothrombin time (s) & 36.4 \\
\hline Uric acid (mg/dL) & 2.0 & Activated partial thromboplastin time (s) & 12.2 \\
\hline Plasma osmolality (mOsm/kg) & 256 & Blood gas analysis & \\
\hline \multirow[t]{4}{*}{ C-reactive protein $(\mathrm{mg} / \mathrm{dL})$} & 0.3 & $\mathrm{pH}$ & 7.51 \\
\hline & & $\mathrm{pCO}_{2}(\mathrm{mmHg})$ & 37.7 \\
\hline & & $\mathrm{pO}_{2}(\mathrm{mmHg})$ & 100.6 \\
\hline & & $\mathrm{HCO}_{3}^{-}(\mathrm{mmol} / \mathrm{L})$ & 30.2 \\
\hline
\end{tabular}

$\mathrm{mL}$ ) at this time. Those findings might suggest that the immunological activity of SLE was elevated during the development of CNS lupus in our case. Since her diagnosis of highly active SLE was confirmed at that time, our patient was transferred to the Department of Rheumatology for SLE-specific therapy.

\section{Discussion}

We experienced a case of hyponatremia associated with the syndrome of inappropriate secretion of antidiuretic hormone (SIADH) and who further developed lupus erythematosus in the central nervous system (CNS lupus). CNS lupus is a general term indicating SLE complications showing signs and symptoms in the CNS, including lupus cerebritis or psychiatric disorders. The concept concerning
CNS manifestation of SLE is recently further extended as containing dementia or mood disorders associated with SLE, called neuropsychiatric lupus (NPSLE) [2].

At the initial phase of hospitalization in our case, the dilution of body fluid would be presumed as a cause of hyponatremia because the clinical parameters did not show a hypovolemic state or an increase in $\mathrm{Na}$ excretion from the kidney. For the differential diagnosis, hyponatremia concomitant with high concentration of urine sodium showed the possible differential diagnosis of cerebral salt-wasting syndrome (CSWS) and mineral corticoid responsive hyponatremia in the elderly (MRHE). Similarly, the clinical setting of dilutional hyponatremia in this case suggested the possible existence of psychotic polydipsia. CSWS is a hyponatremia caused by renal sodium wasting, and is commonly associated with intracranial diseases, such as cerebral hemorrhage or infarction, which is known to be 


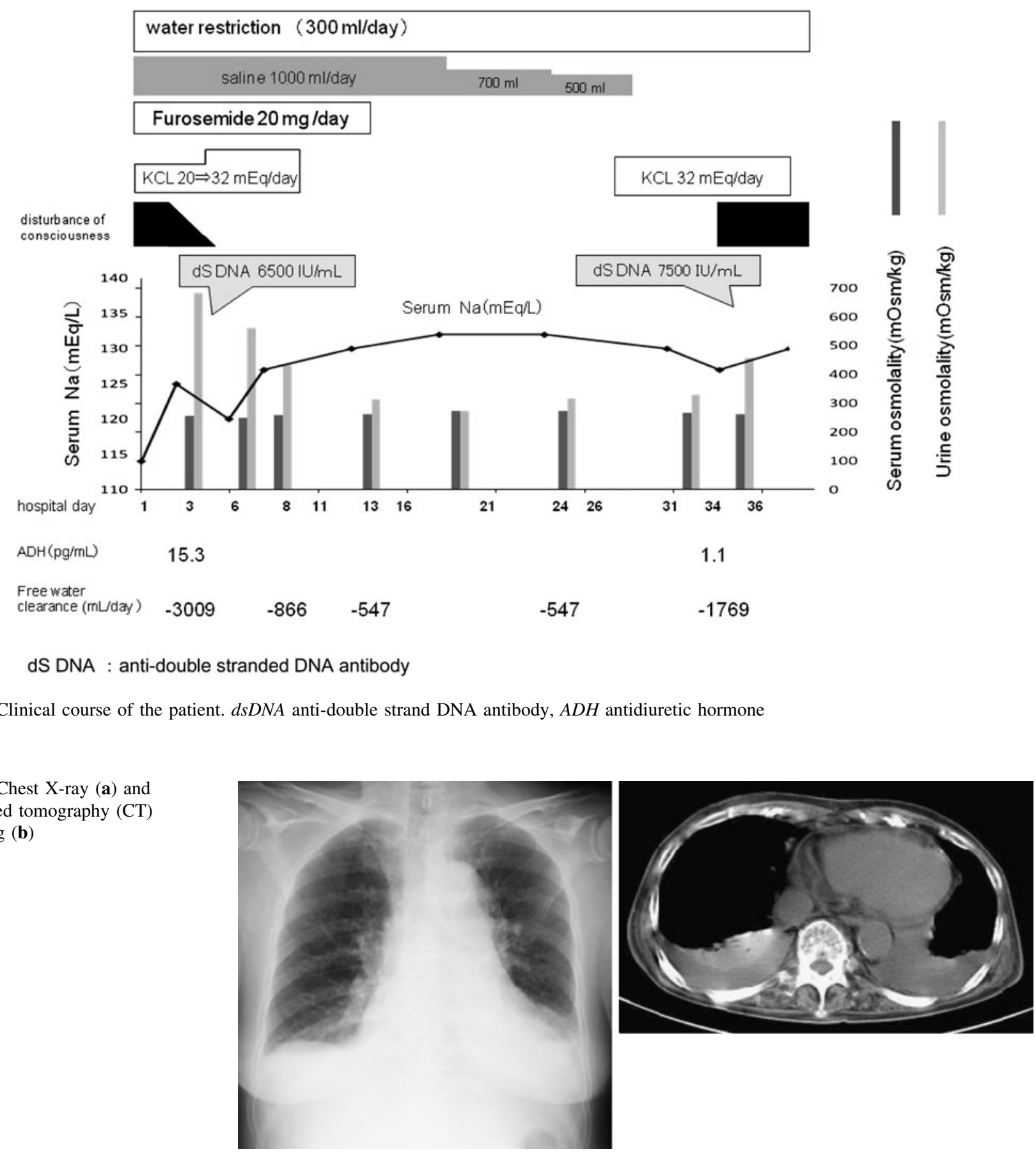

closely related to the overproduction of ANP or BNP [3]. In the present case, the demonstrated high value of urine sodium concentration did not mean over-excretion of urine sodium, but indicates concentrated urine because of impaired free water excretion shown by the negative value of free water clearance $(-3009 \mathrm{~mL} /$ day $)$ and non-elevated sodium excretion ratio (FENa; $1.46 \%$ on admission). Similarly, the presence of MRHE was considered to be deniable because renal salt wasting had not occurred in this case. By the same reason, the involvement of thiazide administration for the development of hyponatremia was considered to be less possible in this case. Psychotic polydipsia is a pathological setting showing dilutional hyponatremia by excess water intake exceeding free water excretion on the basis of the resetting of $\mathrm{ADH}$ regulation. In our case, hypotonic polyuria and clinical history of polydipsia were both negative, indicating that the existence of the disorder would have a low possibility. Finally, in the present case, the lack of increased free water excretion even in the presence of hyponatremia strongly suggested 
Table 2 Laboratory test of pleural effusion

\begin{tabular}{ll}
\hline Color & Pale yellow fluid \\
Pleural opacities & + \\
Fluid specific gravity & 1.033 \\
Ribalta reaction & + \\
Fibrin & + \\
White blood cells (cells/ $\mu \mathrm{L})$ & 2540 \\
Red blood cells (cells/ $\mu \mathrm{L})$ & 1430 \\
Mesothelial cell (cells/HPF) & $10-19$ \\
Punctured fluid protein $(\mathrm{g} / \mathrm{dL})$ & 5.0 \\
Punctured fluid LDH (U/L) & 346 \\
Carcinoembryonic antigen (ng/mL) & 0.7 \\
Carbohydrate antigen $19-9(\mathrm{CA} 19-9)(\mathrm{U} / \mathrm{mL})$ & 2 \\
Adenosine deaminase (U/L) & 25.8 \\
Pleural fluid protein to serum protein ratio & $0.66(>0.5)$ \\
Pleural fluid protein to serum LDH ratio & $0.84(>0.6)$ \\
\hline
\end{tabular}

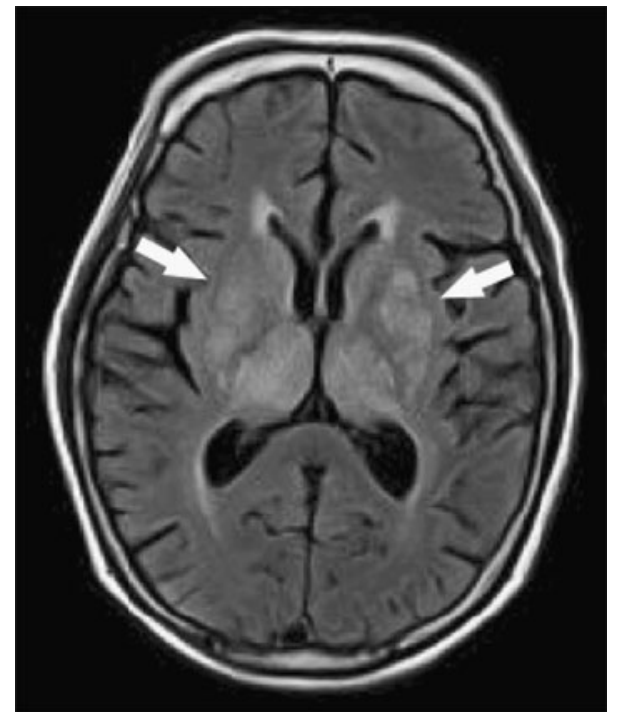

Fig. 3 Brain magnetic resonance imaging (MRI) on the 34th hospital day. Both arrows indicate high-intensity signals in the bilateral basal ganglia and peri-ventricular region

the development of SIADH as a clinical diagnosis. Indeed, the diagnosis was confirmed by an inappropriate decrease in the plasma $\mathrm{ADH}$ concentration in the latter phase of this admission. It is known that SIADH is not rarely complicated with intra-thoracic or intra-cranial disorders, and is occasionally triggered by a variety of medications [4]. Our patient was previously diagnosed with Guillain-Barré syndrome, which is known to be occasionally complicated with SIADH [4]. However, 20 years had passed since the onset of that syndrome, with neither relapse nor re-activation of the disease in our patient. Hence, it might not be considered that the disease would be a trigger for the development of SIADH in the present illness. In addition,
Table 3 Laboratory test of cerebrospinal fluid

\begin{tabular}{ll}
\hline Turbid cerebrospinal fluid & - \\
Bloody cerebrospinal fluid & - \\
Xanthochromia & - \\
Fibrin & - \\
Cerebrospinal fluid cell count & $52 / 3$ \\
Lymphocytes & $24 / 3$ \\
Neutrophils & $24 / 3$ \\
Monocytes & $4 / 3$ \\
Protein (mg/dL) & 191 \\
Lactate dehydrogenase (mg/dL) & 34 \\
Glucose (mg/dL) & 50 \\
Albumin (mg/dL) & 97.4 \\
IgG (mg/dL) & 74.2 \\
IgA (mg/dL) & 6.1 \\
IgM (mg/dL) & 0.9 \\
IgG index & $0.68(>0.65)$ \\
Interleukin-6 (pg/mL) & $386(>4.3)$ \\
Adenosine deaminase (U/L) & 2.9 \\
\hline
\end{tabular}

based on her clinical course, drug-induced SIADH was also excluded. Elevation of the intra-thoracic cavity pressure is known to cause SIADH occasionally. However, accumulated effusion in this case was estimated to be only slight through the observation of chest $X$ ray, suggesting that the elevation of the pressure should be limited. Because a previous report about SIADH assuming the involvement of elevated intra-thoracic cavity pressure as a cause of SIADH demonstrates the accumulation of a large amount of effusion which might be more than half of the thoracic cavity [8], the implication of pleural effusion for SIADH was assessed to be not significant in this case. Those findings suggested that SIADH in this case was not the secondary but, rather, the idiopathic type.

In this case, SLE was strongly suggested upon admission because of the presence of bilateral pleural effusion, marked elevation of anti-DNA antibody $(5120 \times)$, and double-strand DNA antibody $(6500 \mathrm{IU} / \mathrm{mL})$. However, at that time, our patient's clinical and laboratory findings had not fully satisfied the diagnostic criteria of the ARA. CNS lupus was finally diagnosed on the 34th hospital day after the appearance of a consciousness disturbance and pathological tendon reflexes. At that time, our patient satisfied 4 of the 11 items in the diagnostic criteria, including serositis, neural disturbances, immune abnormalities, and the presence of anti-nuclear antibody. Recent works show that SLE associated with CNS complications (CNS lupus) demonstrates various degrees of immune activities [13]. In our patient, the assessment of disease activities by the use of SLEDAI [1] demonstrated 20 points ( 8 points from psychological abnormalities, 8 points from organic brain 
damage, 2 points from pleuritis, and 2 points from high titer of anti-DNA antibody). The averaged SLEDAI score in SLE patients is in the range of $10-15$ points, indicating that our patient showed high immune activity. In addition, our patient displayed a high value of interleukin (IL)-6 in the cerebrospinal fluid $(386 \mathrm{pg} / \mathrm{mL})$. The elevated concentration of IL-6 in cerebrospinal fluid is frequently observed in patients with CNS lupus [6]. This supports the diagnosis of CNS lupus in our patient.

Jennings et al. reviewed 13 SLE cases associated with SIADH [7]. Together with three additional Japanese cases in the literature $[12,14,15]$, we analyzed the immune system activities of SLE cases combined with SIADH in 16 cases. SLEDAI is directly described in 13 cases. The scores of the remaining three cases were calculated by using the clinical and laboratory data described in the literature. Seven of the total of 16 SLE cases with SIADH demonstrate CNS lupus, and their average SLEDAI is $17.1 \pm 5.9$, which is higher than the average score of non-CNS lupus associated with SIADH, $12.5 \pm 4$.1. In addition, Kengne et al. [10] reported that the majority of SLE cases with SIADH had higher SLADAI scores than the cases not complicated with SIADH; the difference was more than 7 points. In our case, the SLEDAI score was 20, which would indicate significantly high disease activity. Thus, the disease activity in our case was compatible with the immunological state of SLE cases associated with CNS complications and SIADH.

It was recently proposed that common factors might be involved in the concomitant development of SLE and SIADH. Siegel et al. [11] revealed that dilutional hyponatremia, which developed occasionally in marathon runners, resulted from SIADH. Concurrently, they found a 40 -fold increase in the concentration of IL-6 after the runners had finished a marathon. Additionally, elevated concentrations of IL- 6 were also demonstrated in the cerebrospinal fluid in some SLE cases complicated with SIADH [5]. Those findings may suggest that the production and/or secretion of IL-6 is closely related to the development of SIADH, especially in cases with SLE. In addition to IL- 6 , the implication of IL- 8 or interferon- $\alpha$ is also proposed as an accelerating factor of SIADH development [9], although the involvement of those factors in our case was not clear. While the relationship between inflammatory cytokines and the development of SIADH has not been fully elucidated, those cytokines might play some critical roles in the development of SIADH in cases with autoimmune disease or chronic inflammatory disorders.

Conflict of interest The authors have stated that they have nothing to disclose.

\section{References}

1. Bombardier C, Gladman DD, Urowitz MB, Caron D, Chang CH. Derivation of the SLEDAI. A disease activity index for lupus patients. The Committee on Prognosis Studies in SLE. Arthritis Rheum. 1992;35:630-40.

2. Brey RL. Neuropsychiatric lupus: clinical and imaging aspects. Bull NYU Hosp Jt Dis. 2007;65:194-9.

3. Cerdà-Esteve M, Cuadrado-Godia E, Chillaron JJ, Pont-Sunyer C, Cucurella G, Fernández M, Goday A, Cano-Pérez JF, Rodríguez-Campello A, Roquer J. Cerebral salt wasting syndrome: review. Eur J Intern Med. 2008;19:249-54.

4. Hannon MJ, Thompson CJ. The syndrome of inappropriate antidiuretic hormone: prevalence, causes and consequences. Eur J Endocrinol. 2010;162(Suppl 1):S5-12.

5. Hirohata S, Hirose S, Miyamoto T. Cerebrospinal fluid IgM, IgA, and IgG indexes in systemic lupus erythematosus. Their use as estimates of central nervous system disease activity. Arch Intern Med. 1985;145:1843-6.

6. Hirohata S, Miyamoto T. Elevated levels of interleukin-6 in cerebrospinal fluid from patients with systemic lupus erythematosus and central nervous system involvement. Arthritis Rheum. 1990;33:644-9.

7. Jennings JE, Sundgren PC, Attwood J, McCune J, Maly P. Value of MRI of the brain in patients with systemic lupus erythematosus and neurologic disturbance. Neuroradiology. 2004;46:15-21.

8. Kagawa K, Fujitaka K, Isobe T, Yamasaki M, Miyazaki M, Oguri $\mathrm{T}$, Kohno N. Syndrome of inappropriate secretion of ADH (SIADH) following cisplatin administration in a pulmonary adenocarcinoma patient with a malignant pleural effusion. Intern Med. 2001;40:1020-3.

9. Katsumata Y, Harigai M, Kawaguchi Y, Fukasawa C, Soejima M, Takagi K, Tanaka M, Ichida H, Tochimoto A, Kanno T, Nishimura K, Kamatani N, Hara M. Diagnostic reliability of cerebral spinal fluid tests for acute confusional state (delirium) in patients with systemic lupus erythematosus: interleukin 6 (IL-6), IL-8, interferon-alpha, IgG index, and Q-albumin. J Rheumatol. 2007;34:2010-7.

10. Kengne FG, Decaux G. Inappropriate secretion of ADH and central diabetes insipidus are related to antiphospholipid antibodies in SLE - case report and review of the literature. Nephrol Dial Transplant. 2006;21:3311-5.

11. Siegel AJ, Verbalis JG, Clement S, Mendelson JH, Mello NK, Adner M, Shirey T, Glowacki J, Lee-Lewandrowski E, Lewandrowski $\mathrm{KB}$. Hyponatremia in marathon runners due to inappropriate arginine vasopressin secretion. Am J Med. 2007;120(461):e11-7.

12. Tachikawa M, Hotta S, Ishii K, Tsumabuki S, Ono JT, Akagi R. Overlap syndrome of systemic lupus erythematosus and polymyositis associated with herpes zoster meningitis and SIADH: a case report. Kyushu J Rheumatol. 1991;11:190-3.

13. van Dam AP. Diagnosis and pathogenesis of CNS lupus. Rheumatol Int. 1991;11:1-11.

14. Watanabe T, Mashiko M, Ohira T, Sato T, Arakawa M. Inappropriate secretion of antidiuretic hormone (SIADH) in a patient with systemic lupus erythematosus (SLE) in elderly man: a case report. J Chubu Rheum Assoc. 1993;24:150-1.

15. Yoshida M, Endo S. A case of SIADH caused by tapering of steroid dosage in patient with SLE. Intern Med. 2000;85:1012-5. 